\title{
How Much Can We Trust Major Element Quantification in Bioapatite Investigation?
}

\author{
Daniele Malferrari, ${ }^{* \dagger}$ Annalisa Ferretti, ${ }^{\dagger}$ Maria Teresa Mascia, ${ }^{\ddagger}$ Martina Savioli, $^{\dagger}$ and Luca Medici ${ }^{\S}$ \\ ${ }^{\dagger}$ Department of Chemical and Geological Sciences, University of Modena and Reggio Emilia, Via Campi 103, I-41125 Modena, Italy \\ ${ }^{\ddagger}$ Department of Diagnostics, Clinical and Public Health Medicine, University of Modena and Reggio Emilia, Via Campi 213/b, \\ I-41125 Modena, Italy \\ ${ }^{\S}$ National Research Council of Italy, Institute of Methodologies for Environmental Analysis, C. da S. Loja, Zona Industriale, I-85050 \\ Tito Scalo, Potenza, Italy
}

\section{Supporting Information}

ABSTRACT: Bioapatite is probably the key factor in the unreplicated success of vertebrates. Chemical data on bioapatite composition can be achieved on a solid sample by using different analytical tools such as spectroscopic and spectrometric methods. As analytical outputs can be affected by the physical-chemical characteristics of the sample matrix, an internal standard is usually required to correct and validate the results. Bioapatite lattice can accommodate iso- and heterovalent substitutions during life or diagenesis varying its chemical composition through (geological) time. If on the one hand, this makes bioapatite a unique archive of physical and chemical information for both the living cycle and the events occurring after death, on the other, it excludes the identification of a sole internal standard. Here, we propose a method to measure major element concentration with specific care for $\mathrm{P}, \mathrm{Ca}, \mathrm{Mg}, \mathrm{Na}, \mathrm{K}, \mathrm{Si}, \mathrm{Al}$, and $\mathrm{Fe}$, which are the main substituent atoms in bioapatite, through homemade matrix-matched external calibration

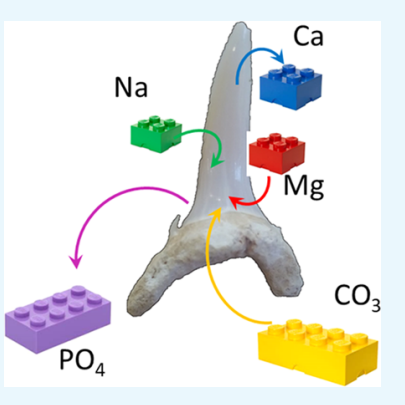
standards for laser ablation inductively coupled plasma mass spectrometry (LA-ICPMS). We tested the method on living and fossil shark teeth, critically comparing the results obtained using other analytical techniques and certified external standards. We demonstrated that matrix-matched calibration in LA-ICPMS is mandatory for obtaining a reliable chemical characterization even if factors such as matrix aggregation variability, diverse presence of volatile compounds, the fossilization footprint, and the instrumental variability can represent further variability parameters.

\section{INTRODUCTION}

Bioapatite played a fundamental role in the evolution of life as it has triggered the unreplicated success of living and fossil vertebrates. In addition, bioapatite represents in fossil organisms a unique archive of physical and chemical environmental information. Chemical data are in this case achieved with a wide range of analytical tools targeted to evaluate not only elemental composition itself but also highlight crystal-chemical evidence. Such techniques include scanning electron microscopy (SEM), mass spectrometry, Xray (micro)diffraction, Fourier-transform infrared spectroscopy, electron microprobe (EMP) analysis, and Raman analysis. $^{1-4}$ Among them, electron microprobe (EMP) and laser ablation inductively coupled plasma mass spectrometry (LA-ICPMS) represent powerful analytical tools that are also potentially able to provide the spatial distribution of major (EMP) and trace (LA-ICPMS) elements in several types of solid matrices. However, as for LA-ICPMS, the absolute amount of materials removed by laser can vary due to differences in the physical-chemical features of the sample matrix and to the related absorption behavior of the used laser wavelength, thus, strongly affecting the accuracy and precision of the resulting data. ${ }^{5,6}$ Therefore, an internal standard is generally in use to adjust variations in the quantity of material ablated during each run. Likewise, the chemical composition determined by comparing the characteristic X-ray intensities obtained from the sample and standard in EMP measurements must be corrected for the matrix effect. Although EMP is generally considered the more appropriate method to gain major element concentration, it is also strictly dependent on the calibrating standards (usually minerals). Moreover, EMP is, undoubtedly, more expensive and less diffused than other instruments.

In fossil and living organisms with calcium carbonate matrix, calcium is unequivocally adopted as internal standard according to the nearly constant stoichiometry of $\mathrm{CaCO}_{3}$ (i.e., lack of relevant iso- and heterovalent substitutions of $\left.\mathrm{Ca}^{2+}\right)$. On the other hand, when dealing with organisms with a phosphate matrix (i.e., bioapatite), it is not a trivial matter to adopt a unique internal standard. In fact, hydroxyapatite (HA), which is the main form of bioapatite in living and fossil organisms, may accommodate chemical substitutions (typically with carbonate ions) both in the phosphatic (A-type substitutions) and hydroxylic (B-type substitutions) sites of its structure. ${ }^{7-11}$ During life, substitutions are limited but once isolated from living tissues, the HA lattice can potentially

Received: July 31, 2019

Accepted: October 3, 2019

Published: October 16, 2019 
accommodate iso- and heterovalent substitutions at all sites during or after burial by diagenesis in consequence of the combination of physical and chemical alteration processes. In this way, the chemical composition of HA can vary over geological time. ${ }^{12-17}$ Moreover, long-term preservation of bioapatite can involve recrystallization and alteration processes and drive to enrichment in other elements [e.g., rare-earth element (REE), $\mathrm{Si}, \mathrm{Fe}, \mathrm{Mg}$, and $\mathrm{Mn}]^{16,18,19}$

For biological matrices, such as invertebrate shells or vertebrate teeth and bones, either living or fossil, several approaches to major element quantification have been proposed, ${ }^{20}$ and a large number among them appeals to National Institute of Standards and Technology (NIST) Standard Reference Materials (SRM) as single and/or multiple point calibrators. More specifically, NIST SRM 610 (and/or NIST SRM 612) trace elements in glass, NIST SRM 1400 bone ash, and NIST SRM 1486 bone meal (below labeled as NIST 610, NIST 612, SRM 1400, and SRM 1486, respectively) are the most used certified standards in measurements of phosphate matrix..$^{21,22}$ However, when an exclusive (i.e., not affected by isomorphic substitutions) internal standard is missing, the matrix-matching constrain remains dramatically unsolved. In fact, while SRM 1400 and SRM 1486 are both bone-based materials, they differ in their organic content [0.87 and 31.5 wt \% by mass loss on ignition (LOI), respectively],,$^{21,22}$ which can affect ablation rates. Likewise, the drawback of NIST glasses is that the matrix of NIST 610 and NIST 612 is mainly $\mathrm{SiO}_{2}$, so fundamentally different from the HA matrix, resulting in significant analytical biases.

In the literature, possible solutions that do not require the use of the internal standard are mentioned. Guillong et al. proposed to normalize the concentration of all elements as oxides to $100 \mathrm{wt} \%$ after external calibration against reference glasses. ${ }^{23}$ Following a similar approach, Liu et al. described an internal standard-independent calibration strategy for LAICPMS analysis of anhydrous minerals and glasses based not only on the normalization of the sum of all metal oxides to 100 wt $\%$ but also introducing a matrix correction factor that considers the concentration and the net count rates of an analyte measured in the sample and in the reference material for calibration. ${ }^{24}$

Our research is aimed to explore similar paths, by comparing results obtained using different calibration standards as external calibrators in a multianalytical approach. We tested diverse calibration strategies for quantifying major elements in fossil and living bioapatite shark teeth using X-ray fluorescence (XRF), LA-ICPMS, and inductively coupled plasma optical emission spectroscopy (ICP-OES), the latter on acid-digested samples. We prepared a series of in-home HA matrix-matched standards (HMMS) and used them as external calibrating curve for LA-ICPMS and XRF to measure concentration of major elements (P, Ca, $\mathrm{Mg}, \mathrm{Na}, \mathrm{K}, \mathrm{Si}, \mathrm{Ti}, \mathrm{Al}, \mathrm{Fe}$, and $\mathrm{Mn}$ ) reported as oxides wt \% in bioapatite. Later, SRM 1400 and SRM 1486 were used as single-point calibrator to calculate the concentration of the same elements. Results were thus critically compared. Our definitive goal is to develop a reliable method or find conclusions for chemical characterization by LAICPMS of small-sized samples (i.e., 50-500 $\mu \mathrm{m}$, not measurable by XRF and ICP-OES) avoiding the use of EMP, which also deserves some constrains.

As reported above, two structural Ca sites allow various type of cationic substitutions into the lattice, while anionic substitutions occur at the $\mathrm{OH}\left(\mathrm{F}, \mathrm{Cl}, \mathrm{CO}_{3}\right)$ and $\mathrm{PO}_{4}\left(\mathrm{CO}_{3}\right)$ sites. Bioapatites are commonly represented by $\mathrm{HA}$ (i.e., dahllite structure); however, carbonate- and fluoro-substituted hydroxyapatites (i.e., francolite structure) are quite common, thanks to carbonate- and fluoride-enriched mechanisms (up to $1 \%$ in weight) occurring during in vivo mineralization. ${ }^{7,25-27}$ Herein, we will focus on cationic substitutions, and therefore fluorine, carbonate, and other possible substitutions with volatile elements are not dealt in the discussion but only considered as contributing to the loss on ignition (LOI), which will be measured through thermal methods.

\section{MATERIALS AND METHODS}

Samples. Teeth of the widespread Paleogene mega toothed shark Otodus sp. and living Charcharias taurus Rafinesque, 1810 (Figure 1) were selected for our study. Even if shark

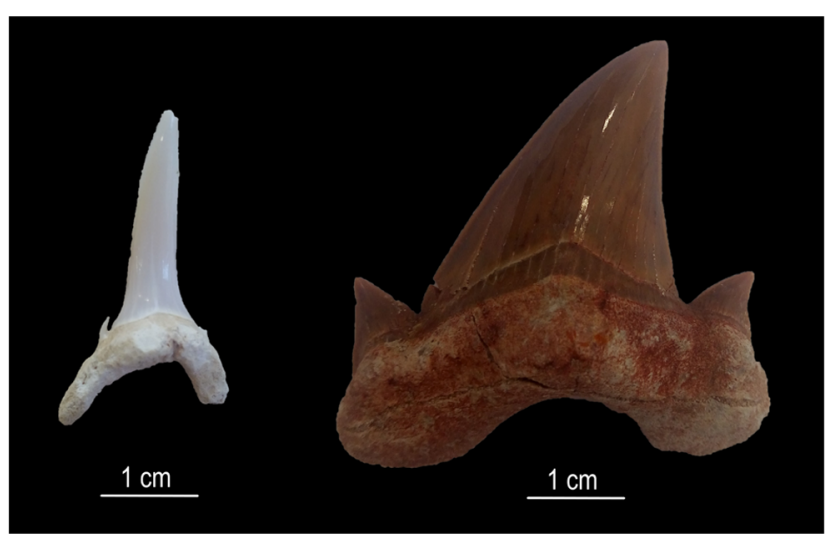

Figure 1. Shark teeth analyzed in this paper: living C. taurus (left) and Paleogene Otodus sp. (right).

teeth, like those of other cartilaginous fish, are mostly composed of fluorapatite rather than hydroxyapatite, we selected such samples as they are widespread in time and space and, therefore, largely investigated. Moreover, as mentioned above, the composition of the anionic site is not relevant to the aims of our investigations.

Teeth were longitudinally cut using a high-precision wire saw (model AGB9001, from Agar Scientific) equipped with a diamond-coated cutting wire. Two separate portions were produced from each tooth. After drying at $30^{\circ} \mathrm{C}$ for $24 \mathrm{~h}$, one piece was incorporated in resin (Figure S1, Supporting Information) and later used for LA-ICPMS measurements. The remaining half was further transversally cut to isolate the dentin and enameloid fractions of the teeth, which, after drying, were separately ground to a fine powder. Resulting materials were finally processed for XRF and ICP-OES analyses, the latter after acid digestion.

Intruments. ICP-MS X series II from Thermo Fisher Scientific equipped with the $213 \mathrm{~nm}$ laser ablation device UP213 from New Wave Research was employed for the sample and standard characterization. Prior to optimizing laser ablation for the bioapatite matrix, the instrument was tuned using the NIST 610 and NIST 612 glasses measuring at instrument-optimized working conditions the intensity of the signals from $\mathrm{U}$ and $\mathrm{Th}$ ( $\mathrm{U} / \mathrm{Th}$ vs $\mathrm{U})$. We fixed to measure abundance ratios between two glasses to gain a double check on bulk measurement accuracy. The laser ablation device employs a single long-working distance lens to focus the beam 
on the sample surface with the possibility to modulate the geometry of the ablation (from a single spot to lines with size varying from 4 to $100 \mu \mathrm{m})$. Standards and samples were mounted to expose their surface to the focal plane of the laser.

Before sample- and matrix-matched standard measurements, the following experimental parameters need to be optimized: (i) laser intensity (\%), i.e., the percentage of the laser beam that reaches the sample surface, can be modulated by changing the geometry of the reflective ends where initial beam is directed; (ii) laser frequency $(\mathrm{Hz})$, i.e., the time when the laser output pulse power remains continuously above half its maximum value; (iii) laser fluence $\left(\mathrm{J} / \mathrm{cm}^{2}\right)$, i.e., the energy delivered per unit area; it depends not only on laser features but also on sample chemical and physical properties, therefore this parameter could not be preset, but is measured during ablation; (iv) ablation line width $(\mu \mathrm{m})$, i.e., the width of the ablation line that can be set varying the slits opening; (v) duration(s) and scan-speed, i.e., the time of persistence of the laser ablation on the ablating surface; (vi) purging gas flow (argon, $\mathrm{mL} / \mathrm{min}$ ), i.e., the volume of gas used to transport the ablated sample to plasma (we kept this parameter constant at $500 \mathrm{~mL} / \mathrm{min}$ ). A preablation, that is an ablation at mild conditions producing a fluency about approximately equal to $1 / 10$ compared to the operating conditions, was always applied to clean up the surface. The approach to reach the optimized ablation conditions on standards and samples will be further discussed.

XRF data were collected using a wavelength dispersive Philips PW 1480 X-ray fluorescence (XRF) spectrometer (Philips, Almelo, The Netherlands) using the methods of Franzini et al. for determination of elemental concentration. ${ }^{28}$ With this method, the fluorescence intensity $I_{j}$ of the element $j$ in a sample containing $N$ elements is related to the mass absorption coefficients of the sample by the formula

$$
I_{j}=\frac{C_{j}}{\sum_{i=1}^{N} K_{j, i} C_{i}}
$$

where $C_{j}$ and $N$ are the concentrations of the elements and the number of elements in the sample, respectively, and $K_{j, i}$ is absorption coefficient. Loss on ignition (LOI) values for samples were obtained from thermogravimetric measurements (see below).

Inductively coupled plasma optical emission spectroscopy (ICP-OES, PerkinElmer Optima 4200 DV) was employed to check element concentration in acid-digested samples after calibration with certified standard solutions.

Thermogravimetry coupled with evolved gas mass spectrometry was employed to find the weight percentage of volatile compounds. Measurements were carried out with a Seiko SSC 5200 thermal analyzer equipped with a quadrupole mass spectrometer (ESS, GeneSys Quadstar 422), which allowed the analysis of gas produced during thermal reactions. Gas sampling by the spectrometer was via an inert, fused silicon capillary system, heated to prevent gas condensing. Gas analyses were carried out to determine the nature of the released chemical species with temperature. Background subtraction was used to obtain the point zero conditions before starting the evolved gas analysis. Experimental conditions were: heating rate $20{ }^{\circ} \mathrm{C} / \mathrm{min}$; heating range $25-$ $1100{ }^{\circ} \mathrm{C}$; purging gas ultrapure helium at a flow rate of 100 $\mu \mathrm{L} / \mathrm{min}$. Mass analyses were carried out in multiple ion detection modes measuring the $m / z$ ratios 18 for $\mathrm{H}_{2} \mathrm{O}, 30$ for
$\mathrm{NO}$, and 44 for $\mathrm{CO}_{2}$, where $\mathrm{m} / z$ is the dimensionless ratio between the mass number and the charge of an ion (these gasses were selected to better define the real contribution to the LOI of organic matter rather than the substituting volatile compounds); SEM detector at $900 \mathrm{~V}$ was employed with $0.5 \mathrm{~s}$ of integration time on each measured mass.

HMMS Preparation. The concentrations of each element in the highest and lowest standard were chosen to bracket as better as possible ranges reported in selected literature papers. ${ }^{15,29}$ Operatively, a stock solution with defined $\mathrm{Na}$ and $\mathrm{K}$ concentration was prepared using pure grade analytical reagents $\left(\mathrm{NaNO}_{3}\right.$ and $\mathrm{KNO}_{3}$, respectively) and Millipore water. Later, appropriate aliquots of the stock solution were separately added to four mixtures formed by proper amounts of ultrapure micronized HA (Sigma-Aldrich) and the oxides $\mathrm{MgO}, \mathrm{SiO}_{2}, \mathrm{TiO}_{2}, \mathrm{Al}_{2} \mathrm{O}_{3}, \mathrm{Fe}_{2} \mathrm{O}_{3}$, and $\mathrm{MnO}_{2}$ (analytical grade reagents, Sigma-Aldrich). To prevent apatite dissolution, immediately after the addition of the solution, the $\mathrm{pH}$ of each aliquot was adjusted to $7.5 \pm 0.1$ using few drops of ammonia diluted solution. Each suspension was mixed and homogenized in an agate mortar and then dried at $30{ }^{\circ} \mathrm{C}$ for 12 $\mathrm{h}$; the resulting powders were then rehomogenized in the agate mortar. Afterward, $750 \mathrm{mg}$ of each powder was pressed for 1 min under $6 \mathrm{t}$ pressure into $12 \mathrm{~mm}$ diameter tablets. ${ }^{30}$ These "standard tablets", each at a different elemental concentration (Table 1), were used to calibrate the LA-ICPMS following the

Table 1. Element Concentrations (Oxide wt \%) in HMMS Calibration Curve

\begin{tabular}{lrrrr} 
& HMMS 1 & HMMS 2 & HMMS 3 & HMMS 4 \\
$\mathrm{SiO}_{2}$ & 1.76 & 0.99 & 0.39 & 0.01 \\
$\mathrm{Al}_{2} \mathrm{O}_{3}$ & 1.01 & 0.60 & 0.29 & 0.01 \\
$\mathrm{Fe}_{2} \mathrm{O}_{3}$ & 1.30 & 0.86 & 0.38 & 0.05 \\
$\mathrm{TiO}_{2}$ & 0.04 & 0.02 & 0.01 & 0.00 \\
$\mathrm{P}_{2} \mathrm{O}_{5}$ & 24.81 & 29.92 & 33.36 & 34.84 \\
$\mathrm{MnO}$ & 0.04 & 0.02 & 0.01 & 0.00 \\
$\mathrm{MgO}$ & 1.64 & 0.98 & 0.44 & 0.11 \\
$\mathrm{CaO}$ & 32.67 & 39.39 & 43.91 & 45.87 \\
$\mathrm{Na} 2$ & 1.73 & 0.76 & 0.26 & 0.11 \\
$\mathrm{~K} 2 \mathrm{O}$ & 0.71 & 0.47 & 0.26 & 0.08 \\
$\mathrm{LOI}$ & 34.30 & 25.98 & 20.70 & 18.91 \\
\hline
\end{tabular}

analytical procedure discussed in Nardelli et al. and better detailed in the following. ${ }^{31}$ Likewise, $300 \mathrm{mg}$ of each powder was employed to calibrate XRF following an approach like those reported in Castellini et al. ${ }^{32}$

LA-ICPMS Calibration. Our first goal was to optimize the ablation conditions, as the amount of material removed by the laser beam in standards and samples strongly reflects their physical-chemical properties (hardness, massiveness, density, etc.). We initially applied mild ablation conditions setting laser intensity at $40 \%$, with a frequency of $5 \mathrm{~Hz}$ and tracing $55 \mu \mathrm{m}$ width ablation lines for a duration of $240 \mathrm{~s}$. Such laser setting was applied to HMMS and produced fluence values close to those reported by Willmes et al. for bioapatite matrix samples. ${ }^{13}$ We have chosen applying ablation lines instead of single spot ablations as the latter can be affected by laserinduced elemental fractioning. This side effect may occur when a large number of shots is carried out in close sequence as a consequence of the thermal effects taking place in the vicinity of the ablation crater and of the increasing degree of elemental 
fractioning occurring when ablating for a long time and, therefore, from ever deeper cavities.

The mass spectrometer was then preliminarily calibrated with HMMS at the above-reported ablation conditions and, later, tablet prepared with SRM 1400, SRM 1486, and with pure HA (12 mm diameter, $750 \mathrm{mg}$ weight, $6 \mathrm{t}$ pressed) were analyzed as unknown samples. Ablation conditions were then modulated and optimized (Table S1, Supporting Information) as long as the concentrations measured for $\mathrm{Ca}$ and $\mathrm{P}$ in SRM standards and HA returned values close to those certified or stoichiometric (Figure 2). These ablation conditions were then

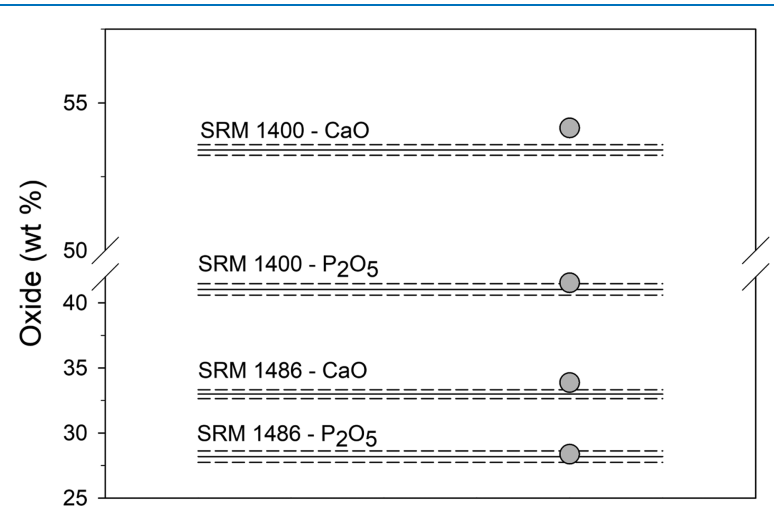

Figure 2. Feedback on the selected calibration parameters as highlighted by the measured concentration of $\mathrm{Ca}$ and $\mathrm{P}$ (filled circles, reported as oxide weight \%) in SRM 1400 and SRM 1486. Assigned values (SRM data sheets) are indicated by solid lines along with the associated expanded uncertainty (dashed lines).

applied to HMMS, SRM standards, and shark teeth. Precision and accuracy were within $\pm 1 \%$. Ti and $\mathrm{Mn}$ detected by LAICPMS were always below $0.01 \mathrm{wt} \%$ and this result was also confirmed by XRF and ICP-OES. As regards $\mathrm{Mn}$ in SRM standards, this limit also agrees with the concentrations (not certified) reported in the data sheets (17 and $1 \mu \mathrm{g} / \mathrm{g}$ for SRM 1400 and 1486, respectively), whereas $\mathrm{Ti}$ concentrations are not reported. However, as $\mathrm{Ti}$ and $\mathrm{Mn}$ do not play a relevant role in isomorphic substitutions in bioapatite, we did not experiment with other methods to better refine their concentrations that will be not reported and further commented in the Results and Discussion section.

\section{RESULTS AND DISCUSSION}

Table 2 reports the measurements on teeth obtained with the different analytical methods. The chemical formulae were calculated assuming ideal stoichiometry and normalized on the basis of $16(\mathrm{~A}+\mathrm{T})$-site cations, ${ }^{33}$ according to the general apatite formula $\mathrm{A}_{10}\left(\mathrm{TO}_{4}\right)_{6} \mathrm{X}_{2}$, where A stands for $\mathrm{Ca}^{2+}, \mathrm{Mg}^{2+}$, $\mathrm{Na}^{+}, \mathrm{K}^{+}, \mathrm{Fe}^{3+}$, and $\mathrm{Al}^{3+}$, whereas the tetrahedral T-site is occupied by $\mathrm{P}^{5+}, \mathrm{Si}^{4+}, \mathrm{Al}^{3+}$. The normalization must satisfy the equation

$$
\frac{\text { moles }(\mathrm{Ca}+\mathrm{Mg}+\mathrm{Na}+\mathrm{K}+\mathrm{Fe}+\mathrm{Al}+\mathrm{P}+\mathrm{Si})}{k}=16
$$

where $k$ is a numerical constant. The anionic $\mathrm{X}$ site is occupied by $\mathrm{OH}^{-}, \mathrm{F}^{-}, \mathrm{Cl}^{-}, \mathrm{CO}_{3}{ }^{2-}, \mathrm{O}^{2-}$, but it is not necessary to know its chemistry for our aims as it does not influence the normalization of the cationic sites. Likewise, REE, C, and $S$ were not determined and are not considered in the chemical formulae as their absence does not affect the significance of the comparisons among the different techniques. The same normalization procedure applies also to Table 3, which will be discussed later.

The numerical results are in good agreement with those described in literature for living and/or fossil organisms. ${ }^{14,15,29}$ In general, and without considering differences arising from each analytical method, Table 2 shows that the $\mathrm{P}_{2} \mathrm{O}_{5}$ content ranges from 26.01 to $35.01 \mathrm{wt} \%$. The minimal and maximal $\mathrm{P}_{2} \mathrm{O}_{5}$ concentrations were recorded in porous dentin and enameloid of living shark, respectively. Similar considerations also apply to $\mathrm{CaO}$ (35.27 wt \% in living shark dentin and 49.49 wt $\%$ in fossil shark enameloid). In fossil teeth, $\mathrm{SiO}_{2}$ can be primarily ascribed to fossilization (i.e., isomorphic substitutions and, more likely, to inclusions of terrigenous materials, as evidenced by the simultaneous increase of $\mathrm{Al}_{2} \mathrm{O}_{3}$ well evident in enameloid and dentin of Otodus sp., but absent in C. taurus, Figure 3). On the other hand, $\mathrm{Na}$ and $\mathrm{Mg}$ may have been incorporated into the bioapatite lattice also during living cycle. As already evidenced by Nemliher et al., ${ }^{14}$ it is not possible to discriminate which cations are, actually, of biogenic origin or which have been integrated during ageing/fossilization, although it is reasonable that $\mathrm{Al}$ and $\mathrm{Si}$ are incorporated only in very small quantities (a few parts per million) during lifecycle, as evidenced by measurements obtained on $C$. taurus.

It is crucial to highlight that percentage data obtained with LA-ICPMS (Table 2a) strongly differ from those obtained with XRF (Table 2b) and ICP-OES (Table 2c); in particular, sums of percentage concentrations measured through LA-ICPMS on all of the samples are clearly lower than those measured through XRF and ICP-OES. Likewise, atoms per formula unit obtained by applying the method above detailed, do not show a unique trend. Before commenting on these differences, it is opportune to check how concentration values change after calibrating with SRM 1400 and SRM 1486 (single-point calibration). More in detail, SRM 1400 (bone ash) and SRM 1486 (bone meal) were used to measure major element concentrations in fossil and recent teeth, respectively. This procedure did not require the ablation of new areas on the sample surface, as the intensity signals produced by previous ablations and used for quantification with HMMS standards were reelaborated using the signals from SRM standards. In this way, differences in concentration can neither be ascribed to instrumental biases as all of the signals are taken in the same working session, nor to compositional variations of samples. Moreover, it should be stressed that ablation conditions applied to SRM have been optimized through HMMS and, therefore, it would not be possible to set such values a priori using exclusively the one-point calibration method.

Results are reported in Table 3 and, basically, parallel to those illustrated in Table 2 even if with minor discrimination between enameloid and dentin values. Significantly, major elements $\mathrm{Ca}$ and $\mathrm{P}$ analyzed in living shark teeth (Table 3a) show close percentage concentrations for dentin and enameloid, and are in general lower than those detected for dentin and enameloid in fossil teeth (Table $3 b$ ).

Data reported in Table $2 \mathrm{a}$ (XRF) and Table $2 \mathrm{~b}$ (ICP-OES) are in good agreement. In fact, using acid digestion and dilution both for sample and standards (ICP-OES) and matrixmatched solid standards (XRF), the matrix constrain is nearly irrelevant. In fact, at these conditions, ICP-OES and XRF are almost exclusively affected by interelement interference issues (i.e., the effects related to radiation interferences, optical or Xrays, respectively), but not by the overall matrix and the 
Table 2. Chemical Composition (Oxide wt \%) and Atoms per Formula Unit (See Text for Details) for Living C. taurus and Fossil Otodus sp. Shark Teeth Measured with LA-ICPMS after Calibrating with HMMS (a), XRF (b), and ICP-OES (c) ${ }^{a}$

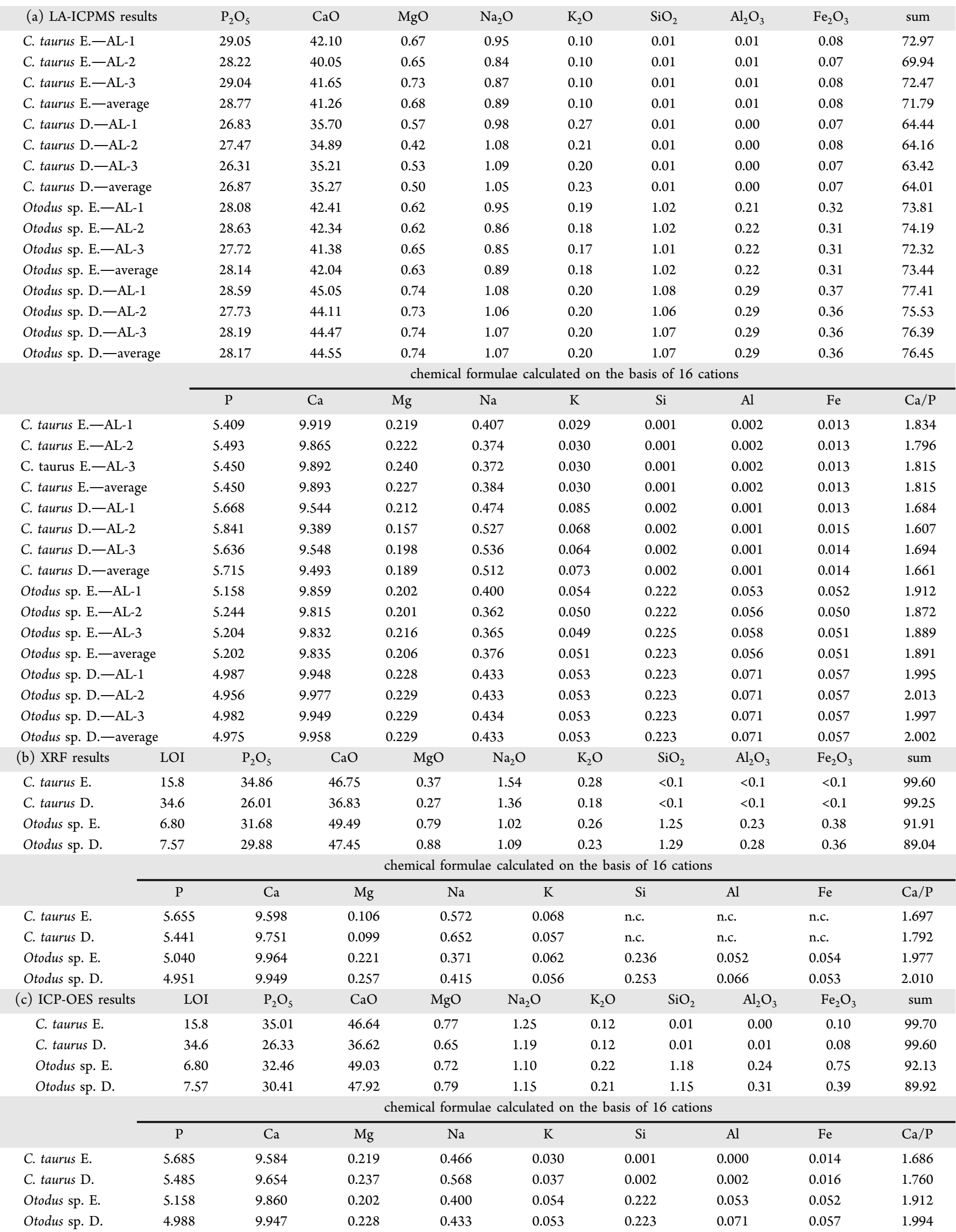

${ }^{a}$ Symbol < denotes concentration below the detection limit (value after the symbol); n.c., not calculable; loss on ignition (LOI) is from thermogravimetric measurement and is included in the sum; AL: ablation line; D.: dentin; E.: enameloid. 
Table 3. Chemical Composition (Oxide wt \%) and Atoms per Formula Unit (See Text for Detail) for Living (a) and Fossil (b) Shark Teeth Obtained with LA-ICPMS after Calibrating with SRM 1486 and SRM 1400, Respectively ${ }^{a}$

\begin{tabular}{|c|c|c|c|c|c|c|c|c|c|}
\hline (a) LA-ICPMS SRM 1486 & $\mathrm{P}_{2} \mathrm{O}_{5}$ & $\mathrm{CaO}$ & $\mathrm{MgO}$ & $\mathrm{Na}_{2} \mathrm{O}$ & $\mathrm{K}_{2} \mathrm{O}$ & $\mathrm{SiO}_{2}$ & $\mathrm{Al}_{2} \mathrm{O}_{3}$ & $\mathrm{Fe}_{2} \mathrm{O}_{3}$ & sum \\
\hline C. taurus E.-AL-1 & 25.15 & 38.32 & 0.59 & 0.79 & 0.10 & 0.00 & 0.01 & 0.07 & 65.02 \\
\hline C. taurus E.-AL-2 & 25.00 & 36.25 & 0.57 & 0.73 & 0.10 & 0.00 & 0.01 & 0.07 & 62.73 \\
\hline C. taurus E.-AL-3 & 24.90 & 36.99 & 0.51 & 0.73 & 0.09 & 0.001 & 0.01 & 0.07 & 63.30 \\
\hline C. taurus E.-average & 25.02 & 37.18 & 0.56 & 0.75 & 0.10 & 0.00 & 0.01 & 0.07 & 63.69 \\
\hline C. taurus D.-AL-1 & 23.93 & 36.69 & 0.58 & 1.01 & 0.29 & 0.01 & 0.00 & 0.06 & 62.57 \\
\hline C. taurus D.-AL-2 & 25.60 & 37.01 & 0.55 & 1.03 & 0.27 & 0.01 & 0.00 & 0.07 & 64.54 \\
\hline C. taurus D.-AL-3 & 25.01 & 35.99 & 0.52 & 1.00 & 0.26 & 0.01 & 0.00 & 0.07 & 62.86 \\
\hline \multirow[t]{3}{*}{ C. taurus D.- average } & 24.85 & 36.56 & 0.55 & 1.01 & 0.27 & 0.01 & 0.00 & 0.07 & 63.32 \\
\hline & \multicolumn{9}{|c|}{ chemical formulae calculated on the basis of 16 cations } \\
\hline & $\mathrm{P}$ & $\mathrm{Ca}$ & $\mathrm{Mg}$ & $\mathrm{Na}$ & $\mathrm{K}$ & $\mathrm{Si}$ & $\mathrm{Al}$ & $\mathrm{Fe}$ & $\mathrm{Ca} / \mathrm{P}$ \\
\hline C. taurus E.-AL-1 & 5.245 & 10.114 & 0.215 & 0.378 & 0.031 & 0.001 & 0.002 & 0.013 & 1.928 \\
\hline C. taurus E.-AL-2 & 5.422 & 9.947 & 0.219 & 0.362 & 0.033 & 0.001 & 0.002 & 0.013 & 1.835 \\
\hline C. taurus E.-AL-3 & 5.348 & 10.054 & 0.195 & 0.357 & 0.031 & 0.001 & 0.002 & 0.013 & 1.880 \\
\hline C. taurus E.-average & 5.337 & 10.039 & 0.210 & 0.366 & 0.031 & 0.001 & 0.002 & 0.013 & 1.881 \\
\hline C. taurus D.-AL-1 & 5.160 & 10.011 & 0.222 & 0.499 & 0.093 & 0.002 & 0.001 & 0.011 & 1.940 \\
\hline C. taurus D.-AL-2 & 5.371 & 9.829 & 0.203 & 0.496 & 0.085 & 0.002 & 0.001 & 0.013 & 1.830 \\
\hline C. taurus D.-AL-3 & 5.391 & 9.817 & 0.199 & 0.493 & 0.084 & 0.002 & 0.001 & 0.013 & 1.821 \\
\hline C. taurus D.-average & 5.308 & 9.885 & 0.208 & 0.496 & 0.087 & 0.002 & 0.001 & 0.012 & 1.862 \\
\hline (b) LA-ICPMS SRM 1400 & $\mathrm{P}_{2} \mathrm{O}_{5}$ & $\mathrm{CaO}$ & $\mathrm{MgO}$ & $\mathrm{Na}_{2} \mathrm{O}$ & $\mathrm{K}_{2} \mathrm{O}$ & $\mathrm{SiO}_{2}$ & $\mathrm{Al}_{2} \mathrm{O}_{3}$ & $\mathrm{Fe}_{2} \mathrm{O}_{3}$ & sum \\
\hline Otodus sp. E.-AL-1 & 26.44 & 40.80 & 0.60 & 0.90 & 0.15 & 1.00 & 0.19 & 0.29 & 70.37 \\
\hline Otodus sp. E.-AL-2 & 26.54 & 40.69 & 0.60 & 0.88 & 0.15 & 1.00 & 0.19 & 0.30 & 70.35 \\
\hline Otodus sp. E.-AL-3 & 26.12 & 41.12 & 0.61 & 0.82 & 0.15 & 0.97 & 0.20 & 0.29 & 70.27 \\
\hline Otodus sp. E.- average & 26.37 & 40.87 & 0.60 & 0.87 & 0.15 & 0.99 & 0.19 & 0.29 & 70.33 \\
\hline Otodus sp. D.-AL-1 & 28.11 & 44.85 & 0.74 & 1.00 & 0.20 & 1.01 & 0.31 & 0.32 & 76.55 \\
\hline Otodus sp. D.-AL-2 & 27.73 & 44.11 & 0.73 & 1.06 & 0.20 & 1.06 & 0.29 & 0.35 & 75.52 \\
\hline Otodus sp. D.-AL-3 & 28.01 & 44.21 & 0.70 & 1.04 & 0.20 & 1.03 & 0.32 & 0.33 & 75.86 \\
\hline \multirow[t]{3}{*}{ Otodus sp. D.—average } & 27.95 & 44.39 & 0.72 & 1.03 & 0.20 & 1.03 & 0.31 & 0.34 & 75.97 \\
\hline & \multicolumn{9}{|c|}{ chemical formulae calculated on the basis of 16 cations } \\
\hline & $\mathrm{P}$ & $\mathrm{Ca}$ & $\mathrm{Mg}$ & $\mathrm{Na}$ & $\mathrm{K}$ & $\mathrm{Si}$ & $\mathrm{Al}$ & $\mathrm{Fe}$ & $\mathrm{Ca} / \mathrm{P}$ \\
\hline Otodus sp. E.-AL-1 & 5.090 & 9.939 & 0.204 & 0.396 & 0.044 & 0.228 & 0.050 & 0.049 & 1.953 \\
\hline Otodus sp. E.-AL-2 & 5.114 & 9.921 & 0.204 & 0.388 & 0.044 & 0.227 & 0.051 & 0.051 & 1.940 \\
\hline Otodus sp. E.-AL-3 & 5.035 & 10.029 & 0.205 & 0.363 & 0.044 & 0.220 & 0.054 & 0.050 & 1.992 \\
\hline Otodus sp. E.- average & 5.079 & 9.963 & 0.204 & 0.382 & 0.044 & 0.225 & 0.052 & 0.050 & 1.962 \\
\hline Otodus sp. D.-AL-1 & 4.960 & 10.015 & 0.230 & 0.404 & 0.053 & 0.210 & 0.077 & 0.050 & 2.019 \\
\hline Otodus sp. D.-AL-2 & 4.956 & 9.978 & 0.229 & 0.433 & 0.053 & 0.223 & 0.071 & 0.056 & 2.013 \\
\hline Otodus sp. D.-AL-3 & 4.988 & 9.964 & 0.219 & 0.425 & 0.054 & 0.217 & 0.080 & 0.053 & 1.998 \\
\hline Otodus sp. D.- - average & 4.968 & 9.986 & 0.226 & 0.420 & 0.053 & 0.217 & 0.076 & 0.053 & 2.010 \\
\hline
\end{tabular}

${ }^{a}$ The integrated signals from samples are the same from Table 2 (same ablation lines). AL: ablation line; D.: dentin; E.: enameloid.

physical properties of the sample. Likewise, variation in intensity signals and, therefore, in concentration values arising from the different abundance of volatile compounds in the sample in ICP-OES and XRF are solved as well. In fact, volatile molecules are removed during acid digestion (ICP-OES); otherwise, their contribution, when the total amount is known, can be easily accounted during data elaboration (XRF).

On the other hand, volatile compounds can play a predominant role in affecting concentration values when they are dispersed in the aerosol produced by laser ablation. Actually, as clearly shown by the thermogravimetric curves and mass spectrometry of the gases evolved during heating (Figures S2-S5, Supporting Information), the difference in concentration in both enameloid and dentin of living shark teeth is high (overall weight loss 15.8 and 34.6 wt \%, Figures S2a and $\mathrm{S} 3 \mathrm{a}$, respectively), whereas it is significantly lower in fossil samples (6.80 and 7.57 wt \%, Figures S4a and S5a). In dentin and enameloid of living shark, the major thermal events occurred between 200 and $500{ }^{\circ} \mathrm{C}$ and are mainly related to the thermal decomposition of the organic fraction as evidenced by the intense exothermic reactions (differential thermal analysis curves, Figures S2a and S3a) and by the release of $\mathrm{H}_{2} \mathrm{O}, \mathrm{NO}$, and $\mathrm{CO}_{2}$ (Figures $\mathrm{S} 2 \mathrm{~b}$ and $\mathrm{S} 3 \mathrm{~b}$ ). In contrast, in fossil teeth, in the same thermal range, the weight loss is strongly limited and a clear signal related to the release of $\mathrm{CO}_{2}$ was observed only in dentin (Figure S5b). Furthermore, in fossil enameloid and dentin, two reactions occurring between 700 and $800{ }^{\circ} \mathrm{C}$ producing the release of $\mathrm{CO}_{2}$ are well evident (Figures $\mathrm{S} 4 \mathrm{~b}$ and $\mathrm{S} 5 \mathrm{~b}$ ). First, forming a shoulder between 720 and $750{ }^{\circ} \mathrm{C}$ in enameloid and a peak with maximum at about $730{ }^{\circ} \mathrm{C}$ in dentin, is from the decarbonatation of B-type substitutions in bioapatite frames; ${ }^{34}$ second, higher temperature (maxima at 805 and $792{ }^{\circ} \mathrm{C}$ in enameloid and dentin, respectively) can be related to decarbonation of calcium carbonate present in terrigenous materials as mentioned when discussing chemical data. These reactions, which are less evident in C. taurus, further prove that the complexity of the matrix sometimes depends also on the coexistence of elements 


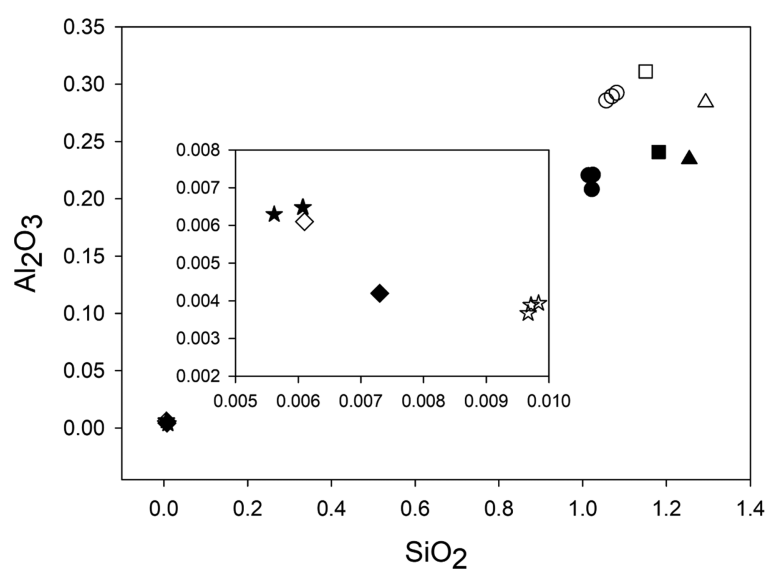

Figure 3. Correlation between $\mathrm{SiO}_{2}$ and $\mathrm{Al}_{2} \mathrm{O}_{3}$ concentrations (oxide weight percent, Table 2) in enameloid (filled symbols) and dentin (open symbols) for fossil Otodus sp. obtained through LA-ICPMS (circles; average values), XRF (triangles), and ICP-OES (squares) and, as better evident in the magnification, for living C. taurus measured with LA-ICPMS (stars; average values) and ICP-OES (diamonds).

with different chemical speciation (i.e., Ca in bioapatite and in carbonate). Moreover, differences in the temperature values at which a thermal event occurs indicate that energy bond varies. This behavior can be related not only to fossilization (fossilized tooth is fully mineralized, i.e., the organic matrix had nearly decomposed over time) but also to anionic substitutions in the bioapatite frame. The discussion of the other reactions related to thermal decomposition of apatite is beyond the aim of this work; nevertheless, they well match with those reported in literature. $^{34,35}$

The presence of volatile compounds in the ablated aerosol and differences in matrix physical properties can result in mass response variations. However, the specific pattern of apparent enrichment and depletion of the various elements that characterize the matrix effect signature probably mirrors a composite interplay between composition and size distribution of ablated particles and their decomposition and ionization mechanisms in the plasma. In fact, it is demonstrated that the LA-ICPMS may also cause elemental fractionation due to the dependence of vaporization, ionization, and ion transmission on the composition and size distribution of the particles in the laser-generated aerosol. ${ }^{36}$ Larger particles or particles that consist of a highly refractory matrix need longer residence time within the ICP or higher gas temperatures for complete vaporization. ${ }^{37}$ Of course, such constrains do not apply to other techniques.

Proper comparisons among the different analytical techniques were required to better evaluate the significances of the obtained results and the analytical goodness of the proposed method. Measurements carried out on dentin of Otodus sp. showed a clear agreement among the three analytical techniques; this portion of the tooth should contain a higher amount of $\mathrm{C}$ in the tetrahedral site as highlighted by the lowest presence of $\mathrm{P}$, fully confirmed by the three methodologies. On the other hand, $\mathrm{Ca}$ and $\mathrm{P}$ atoms per formula unit from enameloid are in good agreement when calculated through LAICPMS and ICP-OES measurements, but are slightly different with respect to those from XRF (Figure 4 and Table S2, Supporting Information). However, according to Lübke et al., ${ }^{29} \mathrm{Ca} / \mathrm{P}$ molar ratio of teeth of fossil sharks should be higher

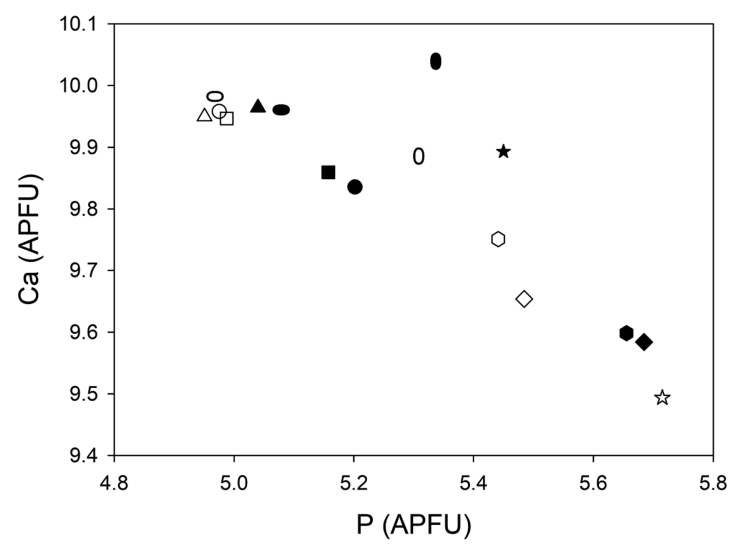

Figure 4. Correlation between $\mathrm{P}$ and $\mathrm{Ca}$ atoms per formula unit in enameloid (filled symbols) and dentin (open symbols) for fossil Otodus sp. obtained through LA-ICPMS (circles; average values; after calibrating with HMMS), XRF (triangles), ICP-OES (squares), and LA-ICPMS (horizontal ellipses; average values; after calibrating with SRM standards) and for living C. taurus obtained through LA-ICPMS (stars; average values; after calibrating with HMMS), XRF (hexagons), ICP-OES (diamonds), and LA-ICPMS (vertical ellipses; average values; after calibrating with SRM standards).

in dentin than that in enameloid, and this behavior was confirmed by all our results (Figure 5).

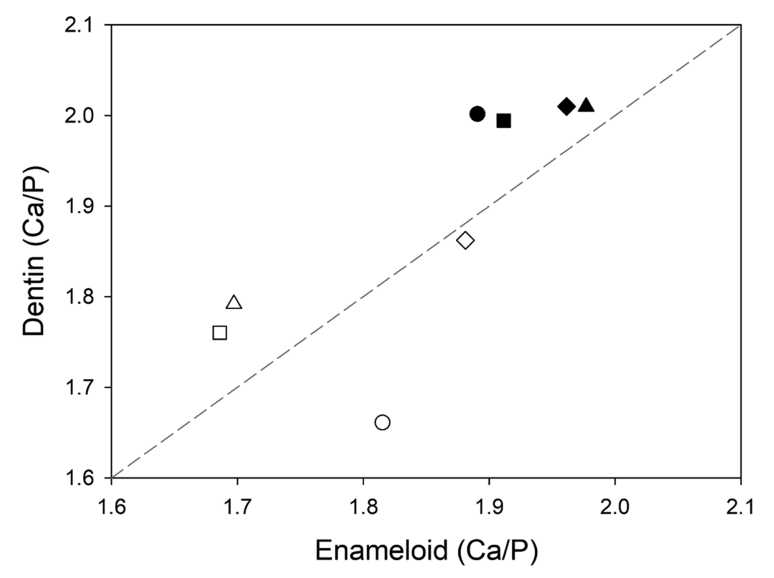

Figure 5. Correlation between $\mathrm{Ca} / \mathrm{P}$ ratios in dentin and enameloid in Otodus sp. (filled symbols) and C. taurus (open symbols) obtained through LA-ICPMS (circles; average values; after calibrating with HMMS), XRF (triangles), ICP-OES (squares), and LA-ICPMS (diamonds; average values; after calibrating with SRM standards).

Measurements performed on living C. taurus teeth are more variable. The most significant differences arise, both for enameloid and dentin, from LA-ICPMS that revealed $\mathrm{Ca}$ and $\mathrm{P}$ atoms per formula unit significantly different with respect to those calculated through XRF and ICP-OES measurements (Table S2); the dissimilarity was confirmed by $\mathrm{Ca} / \mathrm{P}$ molar ratio as well. According to Lübke et al., ${ }^{29} \mathrm{Ca} / \mathrm{P}$ molar ratio of teeth from recent sharks should be higher in enameloid than that in dentin, contrary to fossil sharks. LA-ICPMS results showed (Figure 5) a Ca/P molar ratio in good agreement with the cited literature, both by average values and by single measurements, confirming the effectiveness of the proposed methodology. Average values of $\mathrm{Ca} / \mathrm{P}$ molar ratios obtained by SRM 1400 and SRM 1486 international standards also agree with literature, ${ }^{29}$ although differences between enameloid and 
dentin resulted less sharp (Table S2); nevertheless, single measurements on teeth of living shark are sometimes significantly different from the average values, highlighting possible constrain in their chemical characterization.

\section{CONCLUSIONS}

This study has demonstrated that matrix-matched calibration in LA-ICPMS is a significant and effective condition, mandatory for obtaining a reliable chemical analysis of bioapatite. Uncertainties still concern some aspects: (i) matrix aggregation variability in different parts of the same sample; (ii) greater or lesser presence of volatile compounds (not only organic but also anions such as fluorine, chlorine, and hydroxyls that form possible isomorphic substitutions); (iii) fossilization footprint; (iv) instrumental variability.

The ultimate goal in LA-ICPMS detection is to create an aerosol to be transformed into a mass spectrum fully representing the composition of the ablated material. This cannot be fulfilled in many practical applications because of the variability of the different processes that occur during the generation of the aerosol. Elemental fractionation due to preferential vaporization during the ablation can change the composition in the aerosol formed during ablation and also before the next laser shot occurs. ${ }^{37}$ Likewise, vaporization and ionization of aerosols showing different particle size distributions inside the ICP ion source may further change the relative response of the elements when different materials are sampled.

When matrix-matched calibration standards are available, the processes occurring during LA mainly affect the sensitivity of the method in general. As changes in the ablation rates, particle size distributions, and composition of the aerosol should be identical for the calibration standards and the unknown samples, the major limiting factors should be removed through calibration but only if the physical properties of the sample are homogeneously distributed. It is, of course, mandatory that quantitative data acquisition is carried out at identical ablation conditions, i.e., during the same ablation session.

\section{ASSOCIATED CONTENT}

\section{(5) Supporting Information}

The Supporting Information is available free of charge on the ACS Publications website at DOI: 10.1021/acsomega.9b02426.

Pictures of shark teeth after cutting and incorporation in resin, optimized laser parameters, thermal analyses of enameloid and denting, and atoms per formula unit grouped for sample type (PDF)

\section{AUTHOR INFORMATION}

\section{Corresponding Author}

*E-mail: daniele.malferrari@unimore.it. Web: http:// personale.unimore.it/rubrica/dettaglio/dmalf.

\section{ORCID}

Daniele Malferrari: 0000-0002-0879-1703

\section{Author Contributions}

All authors contributed equally. The manuscript was written through the contributions of all authors. All authors have given approval to the final version of the manuscript.

\section{Notes}

The authors declare no competing financial interest.

\section{ACKNOWLEDGMENTS}

We are grateful to the Centro Interdipartimentale Grandi Strumenti (CIGS; the University of Modena and Reggio Emilia), and especially to Daniela Manzini for LA-ICPMS expertise. Financial support was provided under grant "Fondo Finanziamento Attività Base di Ricerca (FFABR, legge 232/ 2016)" and the Ph.D. program "Models and Methods for Material and Environmental Sciences" of the University of Modena and Reggio Emilia. We thank our colleague Antonio Todaro (the University of Modena and Reggio Emilia) for providing samples.

\section{REFERENCES}

(1) Piga, G.; Santos-Cubedo, A.; Solá, S. M.; Brunetti, A.; Malgosa, A.; Enzo, S. An X-ray Diffraction (XRD) and X-ray Fluorescence (XRF) investigation in human and animal fossil bones from Holocene to Middle Triassic. J. Archaeol. Sci. 2009, 36, 1857-1868.

(2) Li, Z.; Pasteris, J. D. Tracing the pathway of compositional changes in bone mineral with age: preliminary study of bioapatite aging in hypermineralized dolphin's bulla. Biochim. Biophys. Acta, Gen. Subj. 2014, 1840, 2331-2339.

(3) Ferretti, A.; Medici, L.; Malferrari, D.; Savioli, M. Diagenesis does not invent anything new: Precise replication of conodont structures by secondary apatite. Sci. Rep. 2017, 7, No. 1624.

(4) Medici, L.; Malferrari, D.; Savioli, M.; Ferretti, A. Mineralogy and crystallization patterns in conodont bioapatite from first occurrence (Cambrian) to extinction (end-Triassic). Palaeogeogr. Palaeoclimatol. Palaeoecol. 2019, DOI: 10.1016/j.palaeo.2019.02.024.

(5) Longerich, H. P.; Jackson, S. E.; Günther, D. Laser ablation inductively coupled plasma mass spectrometry transient signal data acquisition and analyte concentration calculation. J. Anal. At. Spectrom. 1996, 11, 899-904.

(6) Horn, I.; Guillong, M.; Gunther, D. Wavelength dependent ablation rates for metals and silicate glasses using homogenized laser beam profiles - implications for LA-ICP-MS. Appl. Surf. Sci. 2001, 182, 91-102.

(7) LeGeros, R. Z. Apatites in biological systems. Prog. Cryst. Growth Charact. 1981, 4, 1-45.

(8) Whitenack, L. B.; Simkins, D. C.; Motta, P. J. Biology meets engineering: the structural mechanics of fossil and extant shark teeth. J. Morphol. 2011, 272, 169-179.

(9) Enax, J.; Prymak, O.; Raabe, D.; Epple, M. Structure, composition, and mechanical properties of shark teeth. J. Struct. Biol. 2012, 178, 290-299.

(10) Enax, J.; Janus, A. M.; Raabe, D.; Epple, M.; Fabritius, H. O. Ultrastructural organization and micromechanical properties of shark tooth enameloid. Acta Biomater. 2014, 10, 3959-3968.

(11) Elliott, J. C. Calcium Phosphate Biominerals. In Phosphates: Reviews in Mineralogy and Geochemistry; Kohn, M. J., Rakovan, J., Hughes, J. M., Eds.; Mineralogical Society of America: Washington, DC, 2002; Vol. 48, pp 427-453.

(12) Margariti, E.; Stathopoulou, E. T.; Sanakis, Y.; Kotopoulou, E.; Pavlakis, P.; Godelitsas, A. A geochemical approach to fossilization processes in Miocene vertebrate bones from Sahabi, NE. J. Afr. Earth Sci. 2019, 149, 1-18.

(13) Willmes, M.; Kinsley, L.; Moncel, M. H.; Armstrong, R. A.; Aubert, M.; Eggins, S.; Grün, R. Improvement of laser ablation in situ micro-analysis to identify diagenetic alteration and measure strontium isotope ratios in fossil human teeth. J. Archaeol. Sci. 2016, 70, 102116.

(14) Nemliher, J. G.; Baturin, G. N.; Kallaste, T. E.; Murdmaa, I. O. Transformation of hydroxyapatite of bone phosphate from the ocean bottom during fossilization. Lithol. Miner. Resour. 2004, 39, 468-479.

(15) Keenan, S. W.; Engel, A. S.; Roy, A.; Bovenkamp-Langlois, G. L. Evaluating the consequences of diagenesis and fossilization on bioapatite lattice structure and composition. Chem. Geol. 2015, 413, $18-27$. 
(16) Keenan, S. W. From bone to fossil: A review of the diagenesis of bioapatite. Am. Mineral. 2016, 101, 1943-1951.

(17) Hedges, R. E. M. Bone diagenesis: an overview of processes. Archaeometry 2002, 44, 319-328.

(18) Nielsen-Marsh, C. M.; Hedges, R. E. M. Patterns of diagenesis in bone I: the effects of site environments. J. Archaeol. Sci. 2000, 27, 1139-1150.

(19) Penel, G.; Leroy, G.; Rey, C.; Bres, E. MicroRaman spectral study of the $\mathrm{PO}_{4}$ and $\mathrm{CO}_{3}$ vibrational modes in synthetic and biological apatites. Calcif. Tissue Int. 1998, 63, 475-481.

(20) Jochum, K. P.; Willbold, M. Reference materials in geoanalytical research - review for 2004 and 2005. Geostand. Geoanal. Res. 2006, 30, 143-156.

(21) NIST SRM 1400 Bone Ash Certificate of Analysis; NIST: Gaithersburg, 1992; http://www.nist.gov/srm (accessed Jan 29, 2019).

(22) NIST SRM 1486 Bone Meal Certificate of Analysis; NIST: Gaithersburg, 1992; http://www.nist.gov/srm (accessed Jan 29, 2019).

(23) Guillong, M.; Hametner, K.; Reusser, E.; Wilson, S. A.; Günther, D. Preliminary characterisation of new glass reference materials (GSA-1G, GSC-1G, GSD-1G and GSE-1G) by laser ablation-inductively coupled plasma-mass spectrometry using 193 $\mathrm{nm}, 213 \mathrm{~nm}$ and $266 \mathrm{~nm}$ wavelengths. Geostand. Geoanal. Res. 2005, 29, 315-333.

(24) Liu, Y.; Hu, Z.; Gao, S.; Günther, D.; Xu, J.; Gao, C.; Chen, H. In situ analysis of major and trace elements of anhydrous minerals by LA-ICP-MS without applying an internal standard. Chem. Geol. 2008, $257,34-43$.

(25) LeGeros, R. Z.; Suga, S. Crystallographic nature of fluoride in enameloids of fish. Calcif. Tissue Int. 1980, 32, 169-174.

(26) LeGeros, R. Z.; Go, P.; Suga, S. Fluoride in fish enameloids: Xray diffraction and spectroscopic studies. J. Dent. Res. 1978, 57A, 280.

(27) McConnell, D. Apatite: Its Crystal Chemistry, Mineralogy, Utilization, and Geologic and Biologic Occurrences; Springer Verlag: Wien, 1973; $111 \mathrm{p}$.

(28) Franzini, M.; Leoni, L.; Saitta, M. Revisione di una metodologia analitica per fluorescenza-X, basata sulla correzione completa degli effetti di matrice. Rend. Soc. Ital. Mineral. Petrol. 1975, 31, 365-378.

(29) Lübke, A.; Enax, J.; Loza, K.; Prymak, O.; Gaengler, P.; Fabritius, H.-O.; Raabe, D.; Epple, M. Dental lessons from past to present: ultrastructure and composition of teeth from plesiosaurs, dinosaurs, extinct and recent sharks. RSC Adv. 2015, 76, 6161261622.

(30) Praamsma, M. L.; Parsons, P. J. Characterization of calcified reference materials for assessing the reliability of manganese determinations in teeth and bone. J. Anal. At. Spectrom. 2014, 29, $1243-1251$.

(31) Nardelli, M. P.; Malferrari, D.; Ferretti, A.; Bartolini, A.; Sabbatini, A.; Negri, A. Zinc incorporation in the miliolid foraminifer Pseudotriloculina rotunda under laboratory conditions. Mar. Micropaleontol. 2016, 126, 42-49.

(32) Castellini, E.; Malferrari, D.; Bernini, F.; Brigatti, M. F.; Castro, G. R.; Medici, L.; Mucci, A.; Borsari, M. Baseline studies of The Clay Minerals Society Source Clay montmorillonite STx-1b. Clays Clay Miner. 2017, 65, 220-233.

(33) Brigatti, M. R.; Malferrari, D.; Medici, L.; Ottolini, L.; Poppi, L. Crystal chemistry of apatites from the Tapira carbonatite complex, Brazil. Eur. J. Mineral. 2004, 16, 677-685.

(34) Lafon, J. P.; Champion, E.; Bernache-Assollant, C. D.; Gibert, R.; Danna, A. M. Thermal decomposition of carbonated calcium phosphate apatites. J. Therm. Anal. Calorim. 2003, 72, 1127-1134.

(35) Tõnsuaadu, K.; Peld, M.; Bender, V. Thermal analysis of apatite structure. J. Therm. Anal. Calorim. 2003, 72, 363-371.

(36) Figg, D. J.; Cross, J. B.; Brink, C. More investigations into elemental fractionation resulting from laser ablation inductively coupled plasma mass spectrometry on glass samples. Appl. Surf. Sci. 1998, 127-129, 287-291.
(37) Hattendorf, B.; Günther, D. Laser Ablation Inductively Coupled Plasma Mass Spectrometry (LA-ICPMS). Handbook of Spectroscopy, 2nd enlarged ed.; Gauglitz, G., Moore, D. S., Eds.; WileyVCH Verlag GmbH \& Co. KGaA, 2014; pp 647-698. 